\title{
Singuagens
}

\section{A LINGUAGEM JORNALÍSTICA E O FEMININO NA GUERRA: UM OLHAR SOBRE A PRESENÇA DAS MULHERES NA COBERTURA DA GUERRA DO CONTESTADO}

\author{
Suelen Ramos Grimes (Faculdade SATC) \\ Nádia Regia Almeida Couto (Faculdade SATC) \\ Claudia Nandi Formentin (Faculdade SATC)
}

\begin{abstract}
RESUMO: Este estudo objetiva verificar a cobertura da imprensa catarinense acerca da Guerra do Contestado, mais especificamente do jornal O Dia. Dentre as edições relacionadas ao tema, foram selecionadas oito que abordam a mulher participante do conflito. A pesquisa contextualiza a guerra e também a participação feminina, fundamental em diversos aspectos, inclusive na linha de frente das batalhas. Por meio de autores como Beauvoir, Bourdieu e Wolf, as questões de gênero e construções sociais em torno do tema são evidenciadas, integrando às narrativas de historiadores e autores que se dedicaram a estudar a Guerra do Contestado, como Nilson Thomé, Delmir José Valentini e Marli Auras e fazendo um contraponto com o material encontrado nas páginas de O Dia. Com a análise percebeu-se que as mulheres não tiveram visibilidade perante a cobertura jornalística, com exceção de poucas citações em que são colocadas como vítimas ou ainda satirizadas, como acontece com as "virgens".
\end{abstract}

PALAVRAS-CHAVE: Guerra do Contestado. Mulher. Jornalismo.

\begin{abstract}
The objective of this study is verifying the press' coverage about the Contestado War, specifically the newspaper 'O Dia'. Among these issues, were selected eight editions that deal with women participating in the conflict. The research contextualizes the war and the female participation, fundamental in the battles. Through authors such as Beauvoir, Bourdieu and Wolf as gender issues and constructions around the theme are evidenced, integrating the narratives of historians and those who study the Contestado War, such as Nilson Thomé, Delmir José Valentini and Marli Auras through a counterpoint with the material found in the pages of ' $O$ Dia'. With this analysis it was realized that as women did not have visibility to the news coverage, except for a few references which they are placed as victims or even satirized, as 'virgins'.
\end{abstract}

KEYWORDS: Contestado War. Woman. Journalism.

\section{INTRODUÇÃO}

A Guerra do Contestado aconteceu entre 1912 e 1916 em grande parte do território hoje pertencente a Santa Catarina, nas regiões do Planalto Serrano e do Oeste Catarinense. O conflito teve início em meio à indefinição da posse de terras entre o Paraná e o estado Catarinense, à instabilidade da República, que havia sido proclamada há pouco mais de duas décadas, em 1889, e à lembrança ainda recente da Revolução Federalista, encerrada em 1895 (THOMÉ, 1992).

Na região Contestada viviam famílias caboclas, posseiras de terras, que sobreviviam Linguagens \& Cidadania, v. 19, número especial, jan./dez., 2017. 


\section{S Linguagens}

da agricultura de subsistência. Em meio a este cenário, o governo brasileiro deu uma concessão de terras válida por 90 anos para a Brazil Railway Company, responsável pela construção da estrada de ferro que corta o Estado de Norte a Sul. Para realizar os trabalhos, a empresa contratou mais de 8 mil homens, vindos de outras regiões do país, com a promessa de que iriam melhorar de vida. Ao finalizar as obras, os trabalhadores ficaram desamparados.

Ao mesmo tempo, os caboclos foram desapossados, para que a Ferrovia pudesse passar. Aos poucos, trabalhadores e caboclos viram-se às margens, estando sem local para morar e trabalhar. Uma revolta popular, fundada principalmente no messianismo, teve início, deixando mais de 10 mil mortos nas terras do Sertão Catarinense (THOMÉ, 1992).

A Guerra teve diversas personagens femininas relevantes, entre elas Maria Rosa, que, aos 15 anos, liderou as tropas em combate e ficou conhecida como a Joana D'Arc do Sertão; Chica Pelega, que tinha os conhecimentos passados pelo monge João Maria, e Nega Jacinta, benzedeira bastante popular na região. Apesar de essas mulheres serem conhecidas popularmente no interior catarinense, nunca ganharam notoriedade midiática, a exemplo de Anita Garibaldi ou outras heroínas de seus povos.

Diante desse quadro, essa pesquisa se propôs a observar: "Como foi a cobertura jornalística estadual acerca da Guerra do Contestado e qual a visibilidade dada às mulheres"? Com objetivo geral de verificar nas matérias veiculadas na imprensa sobre a Guerra do Contestado, durante o período mais intenso de conflito, e que teve uma mulher à frente das tropas de sertanejos, Maria Rosa, entre 1914 e 1915, se houve espaço à participação feminina. Os objetivos específicos são observar o discurso das reportagens publicadas sobre o combate; avaliar se as mulheres são lembradas pela imprensa e relembrar as heroínas do Contestado.

Compreende-se que o olhar sobre fatos históricos não é capaz de mudar os acontecimentos, contudo, pode tornar possível o questionamento e a ressignificação da ótica do poder e da construção histórica. Além disso, faz-se importante que as atuais e futuras gerações tenham acesso à trajetória das mulheres antepassadas, inúmeras esquecidas, para que possam encontrar nelas, além do conhecimento histórico, uma fonte de respeito e inspiração.

Para a análise, foram verificadas 440 edições do jornal estadual O Dia, entre os anos de 1914 e $1915^{1}$, momento em que o conflito tornou-se mais visível no Estado. Além disso,

\footnotetext{
${ }^{1}$ Edições disponíveis no acervo da Fundação Catarinense de Cultura.
}

Linguagens \& Cidadania, v. 19, número especial, jan./dez., 2017. 


\section{S. Linguagens}

nesse mesmo período a guerreira Maria Rosa esteve á frente dos caboclos. Os jornais estão disponíveis na Hemeroteca Digital Brasileira² .

\section{CONSTRUÇÕES SOCIAIS: MACHISMO E DESIGUALDADE DE GÊNERO}

A desigualdade entre homens e mulheres é um fato social histórico, que remonta há séculos de segregação e dominação masculina. Para compreender como se estruturam essas relações de poder, alguns pontos são fundamentais na observação da cultura que impera no mundo e nos conceitos que se construíram a partir dela. Para Bourdieu (2002, p. 32):

\footnotetext{
não são as diferenças visíveis entre o corpo feminino e o corpo masculino que, sendo percebidas e construídas segundo os esquemas práticos da visão androcêntrica, tornam-se o penhor mais perfeitamente indiscutível de significações e valores que estão de acordo com os princípios desta visão: não é o falo (ou a falta de) que é o fundamento dessa visão de mundo, e sim é essa visão de mundo que, estando organizada segundo a divisão em gêneros relacionais, masculino e feminino, pode instituir o falo, constituído em símbolo da viralidade, de ponto de honra caracteristicamente masculino.
}

Desta forma, aponta o autor, as singularidades biológicas entre os dois sexos vêm sendo utilizadas como mecanismo de tentativa de afirmação de hierarquização social entre homens e mulheres, o que seria, como ele chama, uma construção arbitrária do biológico, influenciando na percepção social sobre a divisão de trabalho e funções. Portanto "ela legitima uma relação de dominação inscrevendo-a em uma natureza biológica que é, por sua vez, ela própria uma construção social naturalizada" (BOURDIEU, 2002, p. 33).

Para Beauvoir (1970), a separação dos indivíduos entre machos e fêmeas é uma forma reducionista de tratar a questão. A autora afirma que "a maior parte das filosofias tomou-a como admitida sem pretender explicá-la” (BEAUVOUIR, 1970, p. 27). Ela aponta também que a perpetuação da espécie não acarreta na diferenciação sexual, não existindo um motivo biológico que justifique que homens e mulheres sejam tidos como seres diferentes, onde um é superior ao outro.

\footnotetext{
${ }^{2}$ Disponível em http://memoria.bn.br/. Acesso: set. 2016
}

Linguagens \& Cidadania, v. 19, número especial, jan./dez., 2017. 
É portanto, à luz de um contexto ontológico, econômico, social e psicológico que teremos de esclarecer os dados da biologia. A sujeição da mulher à espécie, os limites de suas capacidades individuais são fatos de extrema importância; o corpo da mulher é um dos elementos essenciais da situação que ela ocupa neste mundo. Mas não é êle tampouco que basta para a definir. Ểle só tem realidade vivida enquanto assumido pela consciência através das ações e no seio de uma sociedade; a biologia não basta para fornecer uma resporta (sic) à pergunta que nos preocupa: por que a mulher é o Outro? Trata-se de saber como a natureza foi nela revista através da história; trata-se de saber o que a humanidade fêz da fêmea humana (BEAUVOUIR, 1970, p. 57).

Para Bourdieu (2002), o papel de cada gênero é advindo de uma construção social. Essa construção, juntamente com as supostas justificativas biológicas, vem sendo utilizada ao longo dos anos, em todos os níveis de relação social, "as medidas que excluem as mulheres das tarefas nobres [...], assinalando-lhes lugares inferiores" (BOURDIEU, 2002, p. 33). Desta forma, à mulher vêm sendo impostos os cuidados domésticos, as atividades menos prazerosas, a responsabilidade de cuidar das crianças, enquanto aos homens fica destinado o trabalho fora de casa e o direito de ter uma vida social conforme desejar.

Wolf (1992) afirma, completando a fala de Bourdieu, que todas as gerações de mulheres desde meados do século XIX vêm precisando enfrentar sua "versão" do que, em seu contexto, a autora chama de "mito da beleza", que seria a versão atual de um mecanismo de dominação que impera sob as mulheres articulado coletivamente por um sistema de machismo institucionalizado, com contribuição do sistema econômico, da mídia e da sociedade como um todo. Assim, conforme a autora, não uma justificativa, nem no âmbito biológico nem no histórico para o mito da beleza. Segundo ela "O que ele está fazendo às mulheres hoje em dia é conseqüência unicamente da necessidade da cultura, da economia e da estrutura do poder contemporâneo de criar uma contra-ofensiva contra as mulheres" (WOLF, 1992, p. 16).

Friedan (1971) contextualiza historicamente a forma como esses mecanismos vêm influenciando a vida das mulheres. Segundo a autora, houve um período, após a Segunda Guerra Mundial, em que a "mística feminina", como ela nomeia para se referir à situação de dominação e inferiorização da mulher na sociedade, estava tão bem sedimentada, que praticamente não era questionada pelas mulheres. Os sonhos e conquistas almejados pela maioria das mulheres estavam em torno do casamento e dos filhos. Tendo seus pensamentos longe dos "problemas do mundo para além das paredes do lar e, felizes em seu papel de 


\section{S Linguagens}

mulher, desejavam que os homens tomassem decisões mais importantes" (FRIEDAN, 1971, p. 20).

Bourdieu (2002) observa que essa cultura de desigualdade atua de muitas formas e, entre elas, diretamente ligada à postura e comportamento da mulher. Ele aponta, como exemplo, que às meninas é ensinado desde a infância a maneira como devem sentar e que não devem ser gordas, entre outras coisas que vêm sempre atreladas de vários aparatos que, naturalizados, parecem inofensivos, como as roupas femininas, com saltos, bolsas e vestidos curtos, que impossibilitam à mulher correr ou até mesmo se defender de uma situação de risco.

O mesmo é observado por Beauvoir (1970), que expõe as limitações do padrão estético:

\footnotetext{
Os costumes, as modas são muitas vezes utilizados para separar o corpo feminino da transcendência: a chinesa de pés enfaixados mal pode andar; as garras vermelhas da estrela de Hollywood privam-na de suas mãos; os saltos altos, os coletes, as anquinhas, as crinolinas destinavam-se menos a acentuar a linha arqueada do corpo feminino do que a aumentar--lhe a impotência. Amolecido pela gordura, ou ao contrário tão diáfano que qualquer esforço lhe é proibido, paralisado por vestidos incômodos e pelos ritos da boa educação, é então que esse corpo se apresenta ao homem como sua coisa (BEAUVOIR,1970, p. 200).
}

Conforme Bourdieu (2002), as divisões e relações sociais de dominação e exploração que estão instituídas entre os gêneros se apresentam, progressivamente, em duas classes com hábitos diferentes e opostos. $\mathrm{O}$ autor afirma que, pelo mundo limitado que é imposto às mulheres, elas acabam condenadas a vivenciar e dar fundamento a essa identidade minoritária.

\section{A GUERRA DO CONTESTADO: UMA REVOLTA SERTANEJA}

A Guerra do Contestado pode ser considerada um dos mais expressivos movimentos sociais que já aconteceu no Brasil, no período da Primeira República. A relevância histórica se dá pelo fato de que o fenômeno reuniu diversas frentes de lutas, entre elas a posse de terra, a preservação dos valores culturais e religiosos, a sobrevivência e a luta contra a imposição do modelo capitalista na vida do campo (SERPA, 1999). 


\section{S Linguagens}

As motivações para o acontecimento dividem a opinião de historiadores, sociólogos, antropólogos e geógrafos e não podem ser consideradas isoladamente.

Para uns, a guerra aconteceu em virtude de questões de limites entre os estados do Paraná e Santa Catarina, aliando-se ao fanatismo dos moradores do local. Para outros, a guerra é expressão de múltiplos fatores dentre os quais se destacam a penetração das relações capitalistas no campo, havendo com isso expulsão dos moradores da terra, introdução de novas relações sociais que rompiam com as relações de compadrio e que provocaram mudanças nas práticas religiosas imprimidas pela Igreja Católica, através dos franciscanos (SERPA, 1999, p.11-12).

Para Thomé (1992), várias foram as origens da guerra. Ele destaca que, de alguma forma, a região do Contestado acabou reunindo diversas circunstâncias específicas que, juntas, levaram a eclodir o confronto armado e a guerra civil entre moradores e forças policiais.

O autor aponta que, "simultânea e coincidentemente", o Contestado reunia mais de 20 mil habitantes, entre eles posseiros, que lutavam por um pedaço de terra, fazendeiros, que defendiam suas propriedades, crentes, que aguardavam nas providências dos monges messiânicos, oportunistas, políticos e coronéis, que encontravam neste cenário uma chance para exercer pressões sobre a questão territorial entre os dois Estados. Neste contexto, Thomé (1992, p. 41), destaca que, "No início, os caboclos lutaram isoladamente, cada qual por suas próprias razões. Aos poucos, foram se agrupando no resumo dos anseios comuns, até formarem um só bloco de resistência, de lutas pelos mesmos ideais e aspirações".

Conforme Valentini (2000), foram as disputas de terra que acabaram denominando o local do conflito como "Terra Contestada" ou apenas "Contestado". Os problemas começaram em 1853, quando o Paraná se desmembrou de São Paulo. O acordo entre os dois estados só foi estabelecido em 1916, tornando-se um dos legados do conflito, que teve início em 1912 e durou quatro anos. Nessa época, os moradores da região onde hoje está o Oeste e o Planalto Catarinense não sabiam a qual Estado pertenciam. Por isso, era comum que desentendimentos com a lei acontecessem entre os Estados e a comunidade.

Como se a situação não pudesse ser mais difícil, a construção de uma Estrada de Ferro, que teve início em 1890 e que ligaria a região Central do Brasil ao Sul do país, tornouse motivo de intenso conflito entre os posseiros de terra e a empresa Brazil Railway Company que, aponta Thomé (1992), era de propriedade do empresário norte-americano Percival Linguagens \& Cidadania, v. 19, número especial, jan./dez., 2017. 


\section{Linguagens}

Farquhar e tinha como objetivo, além da construção da via férrea, a exploração da madeira e a colonização das terras no entorno da ferrovia, com a ramificação da companhia através da Brazil Lumber and Colonization Company.

Conforme Valentini (2000), a multinacional passou a comandar a obra por volta de 1905. Nessa época, dos 1,4 mil quilômetros a serem construídos, apenas 599 quilômetros haviam sido abertos para o tráfego e apenas cinco anos faltavam para o encerramento do prazo contratual. O autor explica que "esta poderosa Companhia norte-americana, além de controlar ferrovias, controlava também portos, indústrias, empresas pecuárias, madeireiras e de colonização" (VALENTINI, 2000, p. 45).

A concessão feita à empresa, pelo governo brasileiro, previa benefícios, como a cessão de terras em toda a margem da linha férrea, sendo delimitado um raio de 15 quilômetros para cada lado da obra. O tratado impactou diretamente na vida dos caboclos nativos, que passaram a ser desapropriados sem receber nada em troca, pois não possuíam certidões de posse.

Como responsável pela obra em toda a extensão, a companhia passou a efetuar a contratação de mão-de-obra. Conforme Thomé (1992), a empresa oferecia salários compensadores e, em dezembro de 1908, sem nenhum respaldo de legislação trabalhista, já havia atraído pelo menos 4 mil trabalhadores, oriundos das mais diversas partes do País, etnias e formação histórica. Entre pais de família e pessoas honestas, o grupo reunia também ex-presidiários, desertores e fugitivos da Justiça.

De acordo com Thomé (1992), em 1910 o assentamento de trilhos entre os rios Iguaçú e Uruguai havia sido finalizado, reunindo no ano de inauguração 8 mil trabalhadores. Quando a obra terminou, afirma o autor, um grupo voltou para os lugares de origem e outro continuou na Companhia "para o prosseguimento dos serviços em outras linhas, enquanto que muitos optaram por ficar na região, instalando-se nas proximidades dos trilhos, onde construíram seus ranchos em meio a mata virgem" (THOMÉ, 1992, p. 52).

Conforme Auras (2001), os trabalhadores nunca foram conduzidos aos seus locais de origem, como havia sido prometido inicialmente. Em contrapartida, o território também não tinha condições de absorver toda essa mão-de-obra, já que o setor de produção da erva-mate, antes uma das principais atividades econômicas da região, encontrava-se em crise.

Linguagens \& Cidadania, v. 19, número especial, jan./dez., 2017. 


\section{Linguagens \& Cidadania}

Aumentou em muito e rapidamente o número de moradores locais, contribuindo enormemente para o rompimento do frágil equilíbrio social vigente que, aliás, já vinha sofrendo bastante com a privatização da propriedade da terra e com a crise na comercialização do mate (AURAS, 2001, p. 39).

Thomé (1992, p. 54) relata que, a partir de 1911, estes novos habitantes, que eram tidos como "intrusos", acabaram expulsos das margens da via férrea, pois a empresa ordenou a desocupação dos terrenos já demarcados, para que tivesse início a fase de colonização. Sem alternativas, os ex-trabalhadores precisaram adentrar a mata em busca de abrigo. Foi nessas buscas que se encontraram com os caboclos que, também expulsos de suas terras, estavam na mesma situação. $\mathrm{O}$ autor destaca que "sertanejos e ex-trabalhadores da ferrovia partilharam do sofrimento, pois onde se instalassem, logo aparecia um proprietário a reclamar de suas presenças".

Toda essa situação acabou gerando um sentimento de revolta na classe trabalhadora. Como aponta Thomé (1992), esses ex-contratados pela companhia norte-americana eram desprezados, perseguidos e abandonados à própria sorte e, por isso, passaram a odiar os novos habitantes trazidos pela colonização, que consideravam usurpadores de terra. Neste contexto, dominados pela tristeza e pela raiva, os trabalhadores presenciavam o governo apoiar a Companhia no processo de colonização, onde estrangeiros eram colocados nas terras que antes residiam, enquanto eles continuavam desassistidos e sem nenhuma assistência social.

Segundo Valentini (2000), todo esse contexto ocasionou uma mudança profunda na região. Era o marco de que o capitalismo havia chegado e, agora, mostrava sua face. Aquela realidade, que falava em desenvolvimento, progresso e colonização, era desconhecida pelos caboclos que, muito mais simplistas, preocupavam-se apenas com a própria subsistência.

Segundo Auras (2001), por todo o interior do país encontravam-se os "especialistas do sagrado", peregrinos benzedeiros, curandeiros, pessoas que faziam rezas e dominavam o conhecimento das ervas naturais. Para o caboclo do Contestado, a autora aponta que a figura do monge representava uma forma de negação da realidade vigente, que era fortemente opressora. Ela explica que:

a religião é o único apanágio do sertanejo: frente à insegurança e à violência do cotidiano, ela traz a proteção das forças sagradas; frente à impossibilidade de articular respostas coerentes e abrangentes às contradições vividas, ela apresenta um conjunto de certezas fundamentais. Face a um contexto histórico que procura negar até o estatuto de homem ao sertanejo, a práxis religiosa lhe garante a possibilidade Linguagens \& Cidadania, v. 19, número especial, jan./dez., 2017. 
de construir sua própria identidade - pela religião ele reproduzia conhecimentos antigos e pela religião ele criava novos conhecimentos capazes de significar o seu dia-a-dia (AURAS, 2001, p. 49).

Thomé aponta que foram três os monges com maior influência, no entanto, há relatos de mais de cinco homens que tiveram contato com a população cabocla do Sul do País, inclusive nas décadas mais recentes, até 1940. No presente estudo, vamos nos limitar a falar de apenas dois, que foram os mais importantes no desfecho do Contestado: João Maria de Agostinho e seu sucessor, José Maria.

João Maria de Agostinho, segundo Thomé (1992), era um italiano de Turim, nascido em 1801. Conforme o autor relata, ele chegou em Sorocaba em 1844 apenas com documento e se autodeclarou viajante-peregrino. Ele não pedia dinheiro em troca de seus serviços, vivia de esmolas, dormia no chão de pedra e, quando peregrinava, tinha o hábito de plantar cruzes. Conforme Thomé, o monge passou pela região do Contestado entre 1855 e 1875. Depois, acabou desaparecendo misteriosamente.

Depois do desaparecimento de João Maria, por volta de 1912, já com os ânimos da região Contestada exaltados pelas questões envolvendo a ferrovia e as demarcações de terra, começaram, segundo Thomé (1992), a surgir os boatos de que um outro monge peregrinava os sertões: José Maria. Descobriu-se, mais tarde, que o nome de nascimento do monge era Miguel Lucena de Boaventura, natural de Pernambuco. Ele migrou para o Rio de Janeiro e, depois, para o Paraná.

Durante as peregrinações, José Maria apresentava-se como irmão de João Maria e logo ficou bastante conhecido na região. Conforme Thomé (1992), os cablocos associavam a imagem de José Maria à do antigo monge, pela forma como os dois tratavam o povo, dando atenção, aconselhando e pelos remédios que permitiam "curas milagrosas". Auras (2011, p. 59) explica que responder a pergunta de quem era José Maria, para o sertanejo, "não tinha sentido perguntar por isso - importava, sim, que José Maria estava lá com eles, era com eles, era como eles e, sobretudo, demonstrava na sua prática diária ter o poder do sagrado".

No mesmo ano em que apareceu e ganhou popularidade, 1912, José Maria foi convidado pelos moradores de Taquaruçu, na época território de Curitibanos e hoje distrito de Frei Rogério, para participar da tradicional festa de São Bom Jesus. "A festa no arraial de Taquarussu, começou e não terminou mais", diz Thomé (1992). Conforme o autor, José 


\section{S Linguagens}

Maria, como convidado especial, comemorou com os amigos mais próximos que havia feito na região, atendia o povo dia e noite e logo o local se tornou uma concentração de rezas, procissões e bênçãos. O autor observa ainda que o monge só aceitava de seus "pacientes" apenas a alimentação que precisava e sempre recusava as doações em dinheiro. Assim, “Taquarussu logo virou um “quadro santo" e José Maria levava o povo ao delírio" (THOMÉ, 1992, p. 87).

Taquaruçu ficou conhecida como a primeira "Cidade Santa" já que, mais tarde, foi onde organizou-se o primeiro reduto caboclo. Posteriormente, com o avançar do conflito, a concentração acabou desfeita e foi transferida para outros locais. Posteriormente, várias lutas armadas foram travadas ao longo dos redutos, vitimando, inclusive, personagens importantes, como José Maria, que foi morto no primeiro combate, em Irani.

Com o avançar dos conflitos, dezenas de outras regiões do Planalto Catarinense abrigaram redutos "santos", como eram chamados. Eles concentravam a comunidade cabocla organizada e segura e todos os trabalhos eram compartilhados. Conforme Thome (1992), a guerra entre população e Exército vitimou, ao menos, 10 mil pessoas, incluindo mulheres e crianças, deixando um rastro de sangue nas terras do interior catarinense. Apenas nos últimos meses de 1916 é que o conflito se encaminhou para o fim.

\subsection{As Mulheres na Guerra do Contestado}

A participação das mulheres na Guerra do Contestado se deu por diversas frentes, sendo todas consideradas de fundamental importância no decorrer do conflito. A atuação como proveniente da segurança familiar, dos mantimentos alimentícios, do cuidado com os enfermos e com as crianças e na retaguarda da batalha é uma das posições que a mulher camponesa assumiu ao longo dos quatro anos de guerra.

Porém, além destes papéis, as mulheres também assumiram uma posição de fundamental relevância na crença religiosa e também atuaram como guerreiras no campo de batalha, destacando-se algumas personagens entre as mais importantes de todo o conflito. Este estudo irá enfocar principalmente nesses dois últimos aspectos apontados.

Desde o início da aproximação do grupo caboclo com José Maria, como a organização que ocorreu no Taquaruçu, segundo Thomé (1992), José Maria passou a contar com duas 


\section{S Linguagens}

"virgens" (serviçais): Durvalina, de 11 anos, e Teodora, de 12 anos. As meninas eram ajudantes de confiança do monge e ao longo de toda a Guerra do Contestado tiveram influência importante.

Conforme Apolo (2009, p. 216), o imaginário religioso existente no movimento dos caboclos e a trajetória dos monges possibilitaram o surgimento de "porta vozes personificados pelo poder divino em forma de meninas virgens, representantes do messianismo e da inspiração divina com poderes de cura, capazes de estabelecer um elo entre o mundo encantado e o mundo sertanejo".

O primeiro caso foi o da virgem Teodora. Conforme Auras (2001), Teodora tinha 11 anos, quando relatou à família ter visto três homens, incluindo José Maria, em um galpão um pouco afastado. Todos então se dirigiram até o local, onde rezaram e, no entardecer, viram uma luz que subia ao céu. A notícia logo se espalhou pelo sertão e muitos milagres começaram a ser creditados à santidade do monge. A autora (2001, p. 75) aponta que "a intervenção mediadora inicial de Teodora foi importante porque aglutinou pessoas". Com base nas visões de Teodora, o povo sertanejo organizou-se no Taquaruçu, iniciando a primeira Cidade Santa.

Mais tarde, no reduto de Caraguatá, outra jovem se destacou, sendo considerada a "Heroína dos Sertões" e uma das personagens mais importantes de todo o conflito. Maria Rosa

\footnotetext{
era uma adolescente dos seus quinze anos, loura, cabelos crespos, pálida, alegre, de extraordinária vivacidade. Sobre o pai, Elias da Serra, ficou apenas a informação de que era antigo lavrador pelas redondezas. Maria Rosa não sabia ler nem escrever, mas falava com desembaraço. Andava amiúde com vestido branco, enfeitado com fitas azuis e verdes e de penas de pássaros, de todos os matizes, em profusão. Era ela quem nas procissões marchava à frente, carregando uma grande bandeira com a cruz verde. Às vezes permanecia Maria Rosa longo tempo encerrada num pequeno quarto escuro, do qual saía para "transmitir as ordens" que dizia receber diretamente do José Maria, durante períodos extáticos, de vidência. (...) Em geral, o povo dos redutos considerava Maria Rosa uma santa e julgava que ela "tudo sabia". Cumpria o povo, religiosamente, as ordens que dela emanavam. Era encarada como a representante da vontade do monge, de quem conhecia os secretos desejos. Designava os chefes ostensivos, destituía-os dos comandos, sentenciava (QUEIRÓS, 1981, p. 151-152).
}

Conforme Queirós (1981), confirmou-se, através de documentos históricos que Maria Rosa comandava não apenas o seu reduto, que era composto por cerca de 2 mil pessoas, mas 


\title{
S Linguagens
}

também os demais, através de expedições e despachos "oficiais", designando quem seriam os comandantes.

Para Apolo (2009), o papel desempenhado por Maria Rosa foi fundamental no desenrolar das batalhas e resignando à região e ao povo sertanejo uma identidade própria, com um modo de vida próprio. Para a autora, o preconceito comum da época - que prevalece em muitos aspectos nos dias atuais - em relação à mulher não impôs à Maria Rosa a lei do silêncio, "ao contrário, ela é citada por diferentes autores como uma guerreira destemida que encorajava os sertanejos empunhando a "bandeira santa" e participando das batalhas" (APOLO, 2009, p. 218). Para Scapin,

\begin{abstract}
Ameaçada pelo preconceito, não se intimidou em desafiar as leis, as normas e as ordens determinadas por um sistema patriarcal, que impunha à mulher desde o berço até à sepultura, o toque de silêncio. A vida lhe negara a oportunidade para dedilhar as cordas da "rabeca", mas the oferecera a chance de apertar o gatilho do "mosquetão". Indômita guerreira, que no calor das batalhas, encorajava seus comandados empunhando a bandeira da igualdade (SCAPIN, 2005, p. 48).
\end{abstract}

Pozzo (2005) relembra que, naquela época, as mulheres não tinham voz ativa e nem quaisquer direitos como cidadãs, não aprendiam a ler e a escrever e a elas cabia apenas ficarem "em volta do fogão". Porém, mesmo neste contexto, Maria Rosa comandou mais de 5 mil homens. O autor relembra que, além de Maria Rosa, outras mulheres tiveram papéis de destaque no movimento sertanejo, como a donzela Antoninha, Chica Pelega, Dona Dúlcia e muitas outras que não necessariamente estiveram envolvidas com o setor religioso, mas atuaram no cuidado de crianças e enfermos, apoiando os seus maridos e acreditando na luta sertaneja.

Conforme Felippe (1995), Chica Pelega foi uma heroína do Taquaruçu, onde deu a própria vida para salvar crianças e inocentes. Conforme o autor, Chica Pelega na verdade chamava-se Francista Roberta.

Coração compassivo e generoso, logo ao chegar em Taquaruçu, atraiu todas as simpatias, principalmente das crianças e dos enfermos. Assim de imediato chamou a atenção de José Maria, indo aos poucos tornando-se indispensável auxiliar de enfermagem. Em breve aprendeu lidar com os chás, as infusões, o conhecimento e o trato com ervas medicinais (FELIPPE, 1995, p. 95). 


\section{S Linguagens}

Antes mesmo da atuação de Maria Rosa na guerra, Chica Pelega ficou conhecida, já que atuava como curandeira e enfermeira na primeira Cidade Santa, onde aconteceu o primeiro ataque do Exército. Conforme Felippe (1995), Chica estava dentro de uma igrejinha da comunidade, que havia feito de hospital, quando o local foi atacado e bombardeado pelas tropas do governo. Muitas mulheres e crianças morreram sob a proteção de Chica, que também não resistiu ao ataque.

Este desfecho, no entanto, não é aceito por outros historiadores. De acordo com o historiador Luiz Alves, conforme entrevista concedida no dia 17 de julho de 2016, na sua própria residência, para colaboração nesta pesquisa, Chica Pelega não morreu na Guerra. $\mathrm{O}$ historiador afirma que ela estava fora da igreja no momento do ataque e, desta forma, teria acabado sobrevivendo e fugido para viver na clandestinidade posteriormente. Em seu livro Revolta dos Excluídos, Alves apresenta uma linha do tempo dos acontecimentos e em diversos momentos cita Chica Pelega, que aparece sempre fazendo rotas de fuga e esconderijo, com apoio dos redutos.

O historiador afirma ainda que Chica Pelega não foi a única heroína dada como morta. Segundo ele, a própria Maria Rosa "morreu de velhice", no interior da região. "Ela sobreviveu à Guerra e casou-se três vezes. Conheço a família dela e posso afirmar isso com segurança", disse durante a entrevista, explicando que a heroína também viveu sob outro nome, na clandestinidade. "A maioria dos envolvidos, quando a Guerra acabou, precisaram trocar de nome e se esconder, para viver em segurança", afirmou.

Alves também apontou, durante a entrevista, que o papel das mulheres, de modo geral, foi fundamental para o fortalecimento dos redutos. "Elas não só cuidavam da alimentação, como também comandavam as rezas dentro dos redutos. Se for analisar a fundo, elas eram a parte vital dos redutos", observou.

Para Apolo (2009, p. 219-220), "pode-se contemporizar que a liderança feminina se remete à concepção desse movimento por meio de uma perspectiva voltada para o universo mítico religioso". Para a autora as mulheres, então, "foram portadoras de um representativo simbolismo em que as relações de poder e de dominação são compreendidas como sendo a base da construção das manifestações travadas pelos sertanejos durante a Guerra do Contestado" (APOLO, 2009, p. 219-220). Portanto, a crença em torno do messianismo teria 


\section{S Linguagens}

sido um dos motivos para que o preconceito contra a mulher fosse superado, em partes, no conflito, fazendo com que elas ganhassem liderança e autonomia.

Conforme Pozzo (2005), a jornalista Adélia Maria Lopes publicou uma pesquisa no jornal Nicolau, do Paraná, onde apontava que a Imprensa Oficial do Paraná, ano IV, edição 29, dizia que Maria Rosa, na verdade, foi uma lenda criada pelos caboclos, e que a verdadeira origem da guerreira seria a menina Rosa Alves Westphal, nascida em São Cristóvão do Sul, criada no mesmo município, que teria crescido ali, casado e se mudado para Pouso Redondo. "Com intuito de tirar-lhe o valor histórico, como fizeram com os demais heróis desta guerra que foi um verdadeiro genocídio praticado pelo Exército Nacional” (POZZO, 2005, p. 50).

De acordo com o autor, apenas mais tarde, quando veio à tona a versão dos caboclos, comprovadas com extensas pesquisas históricas, é que ficou claro que a Imprensa Oficial do Paraná havia publicado uma falsa informação sobre a heroína dos sertanejos. "E até que não viesse à tona a versão dos perdedores, ou seja, a história real dos acontecimentos, tinha-se as pessoas desse povo heroico e bravo, como bandidos, jagunços e desordeiros" (POZZO, 2005, p. 50).

Segundo o mesmo autor, as mulheres participantes da guerra passaram por uma visão preconceituosa e maldosa, perante as versões "oficiais".

\footnotetext{
As "virgens" eram retratadas como prostitutas, que serviam os intentos bestiais dos comandantes, e soldados do Exército de São Sebastião. Quando na verdade, eram as "virgens" respeitadas por todos, devido suas purezas, pois, na época acreditava-se que as orações ou pedidos de uma "virgem" eram prontamente atendidos por Deus. Todas as mulheres que foram destaques na Guerra Sertaneja foram taxadas de mulheres vulgares, tais como: a "Virgem" Maria Rosa, a "Virgem" Teodora, Donzela Antoninha, Chica Pelega, Dona Querubina, Dona Dúlcia e tantas outras (POZZO, 2005, p. 51).
}

Cardozo (2009) aponta que, enquanto alguns conflitos foram relatados pela televisão e pelo cinema, como é o caso da Guerra dos Canudos e da Revolução Farroupilha, ganhando visibilidade para além das regiões envolvidas e ocasionando, ainda, um autoconhecimento dos habitantes locais com a sua identidade histórica, a Guerra do Contestado não dispõe da mesma atenção.

Sabemos que a Revolução Farroupilha, por exemplo, tem forte significação para as mulheres em decorrência da guerreira Anita Garibaldi. Contudo, Maria Rosa que, assim como 


\section{Singuagens}

Anita, lutou em batalhas sangrentas e, ainda, comandou exércitos inteiros, não é nem ao menos reconhecida pelas novas gerações de sua gente e menos ainda no Estado como um todo o que, em partes, pode ser ocasionado pela falta de visibilidade feminina durante a própria cobertura do combate que, por si só, já demonstra parcialidade.

\section{ANÁLISE DA COBERTURA DO JORNAL O DIA}

\subsection{A cobertura em 1914}

Na primeira matéria analisada, intitulada apenas "Taquarussú" e publicada no dia 21 de janeiro de 1914, o jornal traz um artigo de opinião acerca dos conflitos que envolvem o Contestado. No texto, não há menção às mulheres e os caboclos são apontados como fanáticos e ignorantes:

\footnotetext{
Foram, é verdade, de todo infructiferas as tentativas já feitas para levar por amistosos conselhos aos cérebros conturbados daqueles desgraçados sertanejos que uma ignorância desolada torna capazes dos actos (sic) mais perigosos e insensatos, a convicção do erro em que se acham (O DIA, 21 de janeiro de 1914).
}

Este tipo de artigo pode ser considerado rotineiro nas páginas do diário estadual, que costumava publicar na íntegra os telegramas enviados e recebidos por autoridades públicas, envolvendo a situação dos sertões catarinenses, além de informações repassadas por correspondentes e outros jornais. Habitualmente os textos seguiam este padrão, apontando os caboclos sempre como fanáticos que perderam a razão e, comumente, vangloriando os atos públicos tomados com propósito de dar fim ao conflito, mesmo que estes não estivessem preocupados com o fator social e com as reivindicações do povo sertanejo. Em muitas ocasiões os caboclos são apontados como "povo sem cultura" ou "culturalmente inferior".

$\mathrm{O}$ posicionamento apresentado pelo jornal $\mathrm{O}$ Dia remete às observações de Valentini (2005), quando o autor observa que por muito tempo a imprensa contribuiu para criar um imaginário social de que os caboclos sertanejos foram vilões na Guerra do Contestado, sem levar em consideração o contexto vivenciado pelo povo nativo do interior do estado.

Na segunda matéria, publicada no dia 4 de fevereiro de 1914, a edição publica um artigo originalmente veiculado no jornal "Tribuna de Curityba", onde são defendidas as Linguagens \& Cidadania, v. 19, número especial, jan./dez., 2017. 


\section{S Linguagens}

pessoas que supostamente estariam fazendo esforços para solucionar o conflito. A nota discorre que:

Os factos e acontecimentos são todos ainda palpitantes; no emtanto, espiritos malevolos não trepidam em, veladamente e ás escancaras, assacar accusações a pessoas que para debelarem o movimento subversivo do sertão, não vacilaram, um só instante, em abandonar o doce aconchego do lar, a vida commum da cidade para partilhar de uma campanha ingloria, expondo a propria vida a par de privações sem conta e insanos trabalhos (O DIA, 2 de fevereiro de 1914).

O D’Angelis (1991) contextualiza a situação expondo que todo o conflito foi embasado na entrada do capitalismo no campo, que não respeitou as tradições, cultura e singularidades do povo que já ali residia.

Já na terceira matéria escolhida, publicada no dia 11 de fevereiro de 1914, é apresentada uma série de telegramas e informações provenientes da região interiorana do Estado. No primeiro telegrama, que foi enviado por Lebon Régis ao governador, é observada uma passagem que se refere às mulheres. Diz o telegrama que, "chegam notícias de várias pontes de ter escapado muita gente do reduto, principalmente mulheres, sobre as quaes (sic) as forças evitavam o mais possível fazer fogo, cessando o fogo sempre que se iam retirando em grupo". (O DIA, 11 de fevereiro de 1914). Na continuidade da matéria, em telegrama enviado pelo tenente-coronel Alleluia Pires, ele relata que "nossas forças penetrando o reduto encontraram cerca de 40 cadaveres, entre os quaes algumas mulheres e creanças (sic)". (O DIA, 11 de fevereiro, de 1914)

Conforme Apolo (2009), as mulheres estavam diretamente ligadas à simbologia religiosa que envolvia o conflito, representando a base das manifestações religiosas, que muitas vezes guiavam o povo sertanejo na fé de uma nova vida. A partir destes trechos extraídos do jornal O Dia, pode-se relacionar essas personagens femininas, que acabavam sendo mortas ou tentavam fugir, com o papel da mulher camponesa que, além de prover, cuidar e organizar os redutos, também ficavam responsáveis pelas práticas de fé e orações.

Na matéria publicada no dia 14 de abril de 1914 é constatada a primeira menção à participação das mulheres como protagonistas na organização dos redutos. Na reprodução de um telegrama enviado ao Rio, onde consta o relato de dois homens capturados pelo Exército: "O monge José Maria transmite ordens a meninas "videntes", menores de dez annos, as quaes por sua vez as transmitem aos chefes, e estes ao povo, que obedece a tudo passivamente" (O Linguagens \& Cidadania, v. 19, número especial, jan./dez., 2017. 


\section{Linguagens}

DIA, 14 de abril de 1914).

No texto, a matéria refere-se à virgem Teodora que, conforme Auras (2001), foi a menina que deu início à organização do povo sertanejo através de redutos, aglutinando as pessoas em torno da causa. É possível perceber que, nesta matéria, a referência feita à mulher está em outro contexto, apresentando, desta vez, a participação feminina de maneira ativa, ainda que com certo sarcasmo. De acordo com Apolo (2009), as virgens eram consideradas personificações do divino, que transmitiam as ordens do monge José Maria e, por isso, muito respeitadas entre o povo caboclo.

Em uma entrevista publicada no dia 2 de junho de 1914, intitulada "Os fanaticos - um prisioneiro - entrevista", novamente é feita menção às virgens dos redutos. Consta no trecho que:

\footnotetext{
Devido aos saques ou a outros meios que elle (sic) ignora havia muita roupa, fazendas e mercadorias n'aquele reduto. Meninas - as taes (sic) virgens que dominam os fanaticos - de 6 a 12 anos, que conheceram em suas choupanas escondendo-se dos viandantes por falta de vestidos para lhe cobrirem a nudez, ostentavam agora vestidos diversos (O DIA, 2 de junho de 1914).
}

Neste trecho, percebemos que as meninas acabam sendo vulgarizadas e também acusadas de "dominarem" os fanáticos, além de ladras de vestidos. Ou seja, apesar da ampla questão que envolvia o conflito, do fato de o povo viver em situações precárias e sem qualquer assistência do Estado, a questão acabava resumida a este tipo de interpretação nas páginas do jornal.

A última menção feita à participação das mulheres no ano de 1914 foi no dia 20 de junho, em nota intitulada Os fanaticos (sic), onde é apresentado o relato de sertanejos capturados:

Taes fanaticos afirmam (sic) que em Agosto subiriam em campo para tomar Curitybanos e a zona serrana, visto estarem convencidos que o governo não os pode vencer, pois são protegidos por José Maria. Actualmente (sic) obedecem cegamente a uma menina de 10 annos (O DIA, 20 de junho de 1914).

Podemos observar, nas três últimas matérias em questão, as mulheres e, nesse caso, meninas, são colocadas de maneira pejorativa. Apesar de não ser utilizada uma palavra em específico, isso pode ser observado pelo tom dos textos, que utiliza de aspas e até grafia em 


\section{S Linguagens}

itálico em alguns trechos, para se referir às meninas. Podemos observar que em momento algum o jornalismo buscou debater as questões apontadas por Apolo (2009), que evidencia a importância da participação das meninas e mulheres no conflito. De certa forma, os textos corroboram com o que Pozzo (2005) observa, quando afirma que as virgens eram tratadas como "prostitutas" e que todas as mulheres que se envolveram na Guerra do Contestado eram tidas como vulgares.

\subsection{A cobertura 1915}

A matéria intitulada "Os fanáticos (sic) - ocupação do reducto (sic) de Pedra Branca" traz um relato sobre um dos momentos de combate da guerra. $\mathrm{O}$ jornal enaltece a postura do Estado, de buscar acabar com o movimento organizado pelos caboclos, e observa que mulheres e crianças acabaram mortas após o combate:

É esse feito uma affirmação eloqente da importancia do plano adoptado pelo sr. dr. Felippe Schmidt, afim de dominar de vez, esse infeliz movimento que está perturbando a vida economica do Estado e levando a perturbação e terror aos nossos sertões. Lamentando a dolorosa contengencia do sacrificio de existencias que podiam ser uteis a sociedade, se inspiradas para o bem, levamos os nossos parabens aos civis e praças da nossa briosa polícia que tomaram parte na conquista do Pedras Brancas. (...) Acabo de ter communicação do tenente José Joaquim comandante (sic) força polícia, que foi tomado homtem reducto (sic) Pedra Branca, tendo ficado muitos bandidos mortos e tambem mulheres e crianças porque no ataque e forte tiroteio foi impossivel evitar (O DIA, 19 de outubro de 1915).

O texto em questão volta a remeter a D'Angelis (1991) e Valentini (2005), que atestam a parcialidade da imprensa na cobertura jornalística dos fatos envolvendo o conflito. Além disso, confirmando o que já foi apontado por D’Angelis (1991), vemos novamente o conflito sendo registrado nas páginas da imprensa como uma batalha de "bem contra o mal".

Pelo que foi constatado durante a pesquisa nas páginas de O Dia, pode-se observar que a maioria das notas e matérias publicadas sobre a Guerra do Contestado estavam relacionadas aos relatos dos oficiais do Exército e aos telegramas oficiais. Tal constatação pode ser feita mais uma vez em uma matéria de capa inteira, publicada no dia 4 de novembro de 1915 e contendo uma entrevista do major Januario Cortes, há em uma passagem o seguinte relato: "Nesta ocasião os Piquetes verificaram a existencia de 18 cadaveres do sexo masculino e alguns do feminino e por parte do pessoal dos Piquetes 4 feridos levemente inclusive seu 


\section{S Linguagens}

bravo comandante" (O DIA, 04 de novembro de 1915).

Apesar de ser uma passagem curta, fica explícita a exatidão no número de mortos homens e a indiferença no número de mulheres mortas, o que, conforme Bourdieu (2002), apresenta a discussão sobre relações de poder, onde as mulheres sempre são colocadas abaixo na "hierarquia social", como se valessem menos que os homens.

Para o autor, a organização social que se estabeleceu entre os dois sexos, com o passar dos anos, tornou o masculino "melhor e maior" do que o feminino. Essa construção é responsável por todo o sistema estruturado em relações de poder entre "macho e fêmea", onde as mulheres acabam inferiorizadas, seja no trabalho, na vida em família ou em outras atividades, pelo fato de serem mulheres.

Podemos nos basear em Bourdieu (2002) para interpretar este trecho em específico, em que as mulheres são tidas como insignificantes na contagem dos corpos, mas também para compreender toda a estrutura em que se baseia esta análise, já que vemos as mulheres sendo apagadas a cada linha onde não estão registradas, seja como participantes internas ou como guerrilheiras.

Como foi dito pelo historiador Luiz Alves (2016), a mulher, de modo geral, não é lembrada pela imprensa. Em nenhuma das 440 edições a que esta pesquisa teve acesso constatou-se o nome de alguma das guerreiras Maria Rosa e Chica Pelega, ou mesmo de outras mulheres que tiveram postura de liderança. As referências às mulheres se resume às citações às virgens que são, ainda, colocadas de maneira arrogante pelo jornal. Como foi afirmado por Queirós (1981), comprovou-se através de documentos históricos que Maria Rosa comandou mais de 2 mil homens diretamente, e mais do que isso indiretamente.

Enquanto diversos personagens homens são referenciados pelo nome, inclusive líderes dos caboclos, a heroína sertaneja não é lembrada em nenhuma nota, sendo que a participação dela ia muito além da religiosidade, como apontou Queirós (1981), relatando que ela seguia na linha de frente dos combates.

\section{CONSIDERAÇÕES FINAIS}

Completando um século de seu desfecho, a Guerra do Contestado ainda é, diariamente, sentida na pele por todo o povo da região serrana catarinense, mesmo que Linguagens \& Cidadania, v. 19, número especial, jan./dez., 2017. 


\section{Singuagens}

sutilmente, nas pequenas coisas que formam o cotidiano da população daquela região. Da mesma forma, a herança deixada pelos antepassados é presente e se manifesta através de uma cultura que tem na sua base a coragem, a valentia e a determinação.

Falar sobre esse conflito e, mais especificamente, sobre a visibilidade das heroínas caboclas, objetivo geral deste estudo, se torna uma espécie de dever social e político, já que, como foi observado nesta pesquisa, todo o contingente de sertanejos que lutaram por seus direitos foram tidos, ao menos por parte da imprensa estadual catarinense, como fanáticos, ignorantes, bandidos e muitos outros termos aos quais eram associados.

Com a análise do jornal O Dia, foi constatado que a cobertura jornalística estadual sobre a Guerra do Contestado manteve um posicionamento bastante parcial, publicando constantemente os telegramas das autoridades oficiais, entrevistas com integrantes do Exército e não abordando a causa do conflito de maneira ampla e ética.

Da mesma forma, ficou evidente que à mulher coube apenas pequenas citações em notas e entrelinhas, onde, em momento algum, elas são citadas como participantes ativas, seja no trabalho dentro dos redutos ou na linha de frente das batalhas. Portanto, pode-se dizer que as mulheres não tiveram visibilidade perante os olhos da imprensa catarinense ou, mais especificamente, do jornal O Dia.

Com isso, é possível concluir que o problema-chave desta pesquisa foi respondido e seu objetivo atingido tendo em vista a observação de evidência de que as mulheres são lembradas em poucas ocasiões e, nestas, na maioria aparecem apenas na frase "morreram mulheres e crianças", ou seja, não são lembradas por seus feitos. Quando são, como é o caso das meninas chamadas de "virgens", acabam sendo ridicularizadas. Por fim, a pesquisa se propôs a relembrar as heroínas do Contestado que, indo além dos livros históricos e do imaginário regional, vão se tornando mais presentes como guerreiras e indispensáveis na luta histórica do povo serrano.

Com esta pesquisa também foi possível concluir que as hierarquias sociais, baseadas na desigualdade de gênero, remontam há muito tempo na sociedade e, no século passado, eram ainda mais presentes e enraizadas. De maneira geral, foi possível perceber que, por conta de diversos fatores, incluindo, se não principalmente, o papel da imprensa, resultaram no apagamento das heroínas do Contestado, como Maria Rosa, Chica Pelega e outras tantas personagens importantes do conflito, que mal são conhecidas pelo povo catarinense.

Linguagens \& Cidadania, v. 19, número especial, jan./dez., 2017. 


\section{S Linguagens}

Ao longo da leitura das matérias e notas veiculadas no jornal O Dia pode-se perceber o quanto os homens eram tratados como pessoas importantes, reconhecidos, tendo seus nomes lembrados, mesmo quando se tratava de caboclos, que pelo jornal eram desmerecidos de qualquer respeito. Em diversos momentos personagens masculinos têm seus nomes citados, seus feitos lembrados, suas decisões noticiadas. Contudo, em nenhum momento alguma decisão de comando dada por Maria Rosa, por exemplo, que comprovadamente esteve à frente dos sertanejos no período entre 1914 e 1915, escolhido como foco para esta análise, é mencionada.

\section{REFERÊNCIAS}

APOLO, R. P. O papel da mulher na Guerra do Contestado. In: FRAGA, N. C. (Org.). Contestado: o território silenciado. Florianópolis: Insular, 2009.

AURAS, M. Guerra do Contestado: a organização da irmandade cabocla. Florianópolis: Cortez, 2001.

BEAUVOIR, S. O Segundo Sexo: Fatos e Mitos. São Paulo: Difusão Europeia do Livro, 1970.

BOURDIEU, P. A dominação masculina. 2. ed. - Rio de Janeiro: Bertrand Brasil, 2002.

CARDOZO, P. F. Invisibilidade a ser contestada: um olhar sobre as possibilidades de visibilidade dos caboclos da Guerra do Contestado nos dias atuais. In: FRAGA, N. C. (Org.). Contestado: o território silenciado. Florianópolis: Insular, 2009.

D'ANGELIS, W. Contestado: a revolta dos sem-terras. São Paulo, SP: Ed. FTD, 1991.

FELIPPE, E. J. O último jagunço: folclore na história do Contestado. Curitibanos: Universidade do Contestado, 1995.

FRIEDAN, B. Mística Feminina. Rio de Janeiro: Vozes, 1971.

POZZO, E. Maria Rosa - A que "tudo sabia". In: DOLBERTH, A. (Org.) Maria Rosa - a 'virgem' comandante da guerra sertaneja do Taquaruçu. Curitibanos: Thipograf, 2005.

SCAPIN, A. Uma guerreira em busca de liberdade. In: DOLBERTH, A. (Org.) Maria Rosa a 'virgem' comandante da guerra sertaneja do Taquaruçu. Curitibanos: Thipograf, 2005. 


\section{$\checkmark$ Linguagens}

SERPA, É. A guerra do contestado (1912-1916). Florianópolis: Universidade Federal de Santa Catarina, 1999.

THOMÉ, N. Sangue, suor e lágrimas no chão contestado. Caçador, SC: INCON/UNC, 1992.

VALENTINI, D. J. Da cidade santa à corte celeste: memórias de sertanejos e a guerra do contestado. Caçador - SC: Universidade do Contestado, 2000.

Guerra do Contestado: construção da imagem do caboclo. In: DOLBERTH, A. (Org.) Maria Rosa - a 'virgem' comandante da guerra sertaneja do Taquaruçu. Curitibanos: Thipograf, 2000.

WOLF, N. O Mito da Beleza. Rio de Janeiro: Editora Rocco, 1992. 